\title{
PERCEPÇÃO DOS PAIS SOBRE A VIVÊNCIA NO MÉTODO MÃE-CANGURU
}

\author{
Cláudia Elisângela Fernandes Bis Furlan ${ }^{1}$ \\ Carmen Gracinda Silvan Scochi \\ Maria Cândida de Carvalho Furtado ${ }^{3}$
}

Furlan CEFB, Scochi CGS, Furtado MCC. Percepção dos pais sobre a vivência no método mãe-canguru. Rev Latino-am Enfermagem 2003 julho-agosto; 11(4):444-52.

O presente estudo tem como objetivo analisar a percepção de pais de bebês prematuros sobre a vivência no Método Mãe-Canguru. Trata-se de estudo descritivo, inserido na abordagem qualitativa. Os dados foram coletados a partir de entrevista semi-estruturada com 10 pais, realizada em até 60 dias após a alta do prematuro do Canguru, realizado em um hospital filantrópico do interior do Estado de São Paulo. A percepção dos pais sobre a vivência foi agrupada em quatro núcleos temáticos: flexibilizando a permanência materna no Método Mãe-Canguru; favorecendo a relação mãe-filho e família; completando o crescimento e desenvolvimento do prematuro e desenvolvimento de habilidades para o cuidado com o filho. Os dados obtidos fornecem subsídios para a organização da assistência no Método Mãe-Canguru, tanto sob a perspectiva institucional da equipe atuante como da relação com a clientela, possibilitando a compreensão das dificuldades e significados atribuídos à vivência e otimização do cuidado de enfermagem.

DESCRITORES: método mãe canguru; pais; cuidados de enfermagem

\section{PERCEPTION OF PARENTS IN EXPERIENCING THE KANGAROO MOTHER METHOD}

This study aimed at analyzing the perception of pre-term babies' parents in experiencing the Kangaroo Mother Method. It is a descriptive study with a qualitative approach. Data were collected from semi-structured interviews with 10 parents, held in the first 60 days after the discharge of the pre-term baby from the Kangaroo method, in a philanthropic hospital in the interior of São Paulo State. The parents' perception concerning the experience was grouped in four thematic units: making maternal stay in the Kangaroo Method flexible; favoring the mother-child and family relationship; completing the pre-term newborn's growth and development and developing skills in caring for the child. The obtained data provided information for the organization of care in the Kangaroo Mother Method, from the institutional perspective of the health care team as well as the relationship with clients, which enabled understanding about the difficulties and meanings attributed to the experience and optimization of nursing care.

DESCRIPTORS: kangaroo mother method; parents; nursing care

\section{LA PERCEPCIÓN DE LOS PADRES EN LA VIVENCIA DEL MÉTODO MADRE-CANGURO}

El presente estudio tiene como objetivo analizar la percepción de los padres de bebes prematuros en la vivencia del método Madre-Canguro. Este es un estudio descriptivo, inserido en un abordaje cualitativo. Los datos fueron recolectados a partir de entrevistas semiestructuradas con 10 padres, realizadas en un plazo máximo de 60 días después de la alta del prematuro del Canguro realizado en un hospital filantrópico del interior del Estado de São Paulo. La percepción de los padres con respecto a la vivencia en el Método, fue comprendida en cuatro núcleos temáticos: flexibilizando la permanencia materna en el Método Madre-Canguro; favoreciendo la relación madre-hijo y familia; completando el crecimiento y desarrollo del prematuro y desarrollo de habilidades para el cuidado con el hijo. Los datos obtenidos ofrecen aportes para la organización de la atención en el método Madre-Canguro, tanto en la perspectiva institucional del equipo de salud como de la relación con la clientela, posibilitando la comprensión de las dificultades y significados atribuidos a la vivencia y a la optimización del cuidado de enfermería.

DESCRIPTORES: método madre canguro; padres; atención de enfermería

\footnotetext{
${ }^{1}$ Enfermeira, Mestre em Enfermagem em Saúde Pública, e-mail: rogeriofurlan@netsite.com.br; ${ }^{2}$ Orientador da dissertação, Professor Associado, e-mail: cscochi@eerp.usp.br; ${ }^{3}$ Mestre em Enfermagem em Saúde Pública, Especialista em Laboratório, e-mail: mariacandida@netsite.com.br. Escola de Enfermagem de Ribeirão Preto, da Universidade de São Paulo, Centro Colaborador da OMS para o desenvolvimento da pesquisa em enfermagem
} 
INTRODUÇÃO

A preocupação com os prematuros, desprovidos de contato íntimo materno, provocado pela separação desde o nascimento, é recente, quando programas de estimulação precoce são desenvolvidos e utilizados, incluindo estimulação visual, auditiva e tátil ${ }^{(1-2)}$, recurso utilizado com simplicidade e brilhantismo, espelhando-se nos mamíferos marsupiais, o canguru. Valer-se do calor do corpo materno, do contato pele a pele, do leite materno que não só alimenta, mas imuniza, do amor que estimula e fortalece a criança, são elementos simples que, combinados, salvam vidas em locais onde os recursos humanos e materiais são escassos. Tal estratégia é particularmente importante face ao contexto mundial, em países onde as condições socioeconômicas e $\mathrm{o}$ acesso aos serviços de saúde são escassos. E especial referência é atribuída aos prematuros que ficam mais expostos às condições sociais desfavoráveis, apresentando alto risco de morbi-mortalidade ${ }^{(2)}$.

No Brasil, algumas medidas foram tomadas relativas ao aleitamento materno, através de campanhas nacionais de incentivo e da criação de normas rígidas para a comercialização e propaganda de fórmulas lácteas, bicos artificiais, chupetas e mamadeiras ${ }^{(3)}$. Anos mais tarde, a Constituição Federal, promulgada em 1988, assegurou a licença maternidade de 120 dias, a licença paternidade de 5 dias e o direito às presidiárias a permanecerem com os filhos durante o período de amamentação. Essas medidas limitaram-se ao atendimento das necessidades de bebês a termo e não de prematuros.

O processo político-institucional e administrativo de reestruturação do sistema de saúde do país, ocorrido nas duas últimas décadas e o ideário de humanização na perspectiva de favorecer e manter a relação mãe-filho e família, deixa de ser exclusivo do discurso dos profissionais de saúde, para se constituir em diretrizes de políticas públicas para a assistência ao processo de nascimento.

Um dos movimentos internacionais direcionados à promoção do aleitamento materno é a Iniciativa do Hospital Amigo da Criança (IHAC), cujas bases foram definidas e preconizadas pelo UNICEF (Fundo das Nações Unidas) e pela Organização Mundial de Saúde (OMS) ${ }^{(4)}$. As medidas sugeridas pela IHAC preconizam que mãe e bebê sadios permaneçam juntos desde a sala de parto até o momento da alta hospitalar, em alojamento conjunto e com o aleitamento em livre demanda. Porém, críticas são feitas a respeito desse movimento, pois se dirige ao incentivo do aleitamento materno de bebês sadios, entendendo que o conceito de um Hospital Amigo da Criança é mais do que passos sugeridos e deveria atender também às necessidades do prematuro, havendo, então, propostas de alguns passos (11) direcionados à melhoria do cuidado integral aos neonatos prematuros ou doentes, nas unidades neonatais ${ }^{(5)}$.

O Cuidado Canguru, recentemente, passou a fazer parte das diretrizes políticas de atenção à saúde dos bebês de baixo peso ao nascer e prematuros, estando incluído no Programa de Humanização do Pré-Natal e Nascimento. Assim, com a Portaria n 693, de 05 de julho de 2000, o Ministério da Saúde normatiza a implantação do Método Mãe-Canguru, definido como assistência neonatal que implica no contato pele a pele precoce entre o binômio mãe-filho (recém-nascido de baixo peso, prematuro), de forma crescente, permitindo, dessa forma, maior participação dos pais no cuidado com seu filho ${ }^{(6)}$. Os critérios de inclusão de recém-nascidos no método canguru são a estabilidade clínica e o ganho de peso.

A adoção do Cuidado Mãe-Canguru é estratégia essencial para mudança institucional na busca da atenção à saúde, centrada na humanização da assistência e no princípio da cidadania da família. Mas, a simples implantação do Cuidado Canguru em uma instituição não alcança os objetivos almejados, pois é necessária a capacitação dos profissionais de saúde envolvidos no processo para transformação do modelo assistencial ${ }^{(6)}$. As etapas sugeridas estendem para a promoção do cuidado ao recém-nascido e à sua família. Cada etapa requer subsídios que assegurem à puérpera e ao bebê condições para o aprimoramento do vínculo, a promoção do aleitamento e a capacitação materna do cuidado com o filho. Entre os subsídios estão a vinda diária à unidade de internação, o auxílio para o transporte coletivo às mães que necessitarem, o oferecimento de refeições durante a permanência diurna e de espaço para seu descanso, a realização de palestras e o livre acesso dos pais à unidade neonatal. Dos bebês, exige-se a estabilidade clínica, respiratória e circulatória e para a equipe de saúde pedese a orientação aos pais sobre o Método, a estimulação quanto à manutenção do contato tátil com a criança, apoio e intervenção para a manutenção da produção láctea e armazenamento do leite ordenhado ${ }^{(6)}$.

Pelo exposto, elegemos como objeto de estudo a percepção dos pais de prematuros acerca da vivência 
do Mãe-Canguru, implantado em um hospital filantrópico do interior do Estado de São Paulo, com o objetivo de desenvolver subsídios para a promoção de assistência humanizada à clientela de UTIN.

\section{METODOLOGIA}

É um estudo descritivo, de abordagem qualitativa $^{(7)}$. As entrevistas semi-estruturadas foram realizadas com 10 pais de prematuros, 60 dias após a alta do Método Canguru, realizado em um hospital filantrópico do interior do Estado de São Paulo. O estudo foi iniciado após consentimento da Comissão de Ética da instituição. A entrevista seguiu roteiro contendo dados de identificação e a questão norteadora: fale sobre sua vivência no Método Mãe-Canguru. Após o consentimento pré-informado, as entrevistas foram gravadas, exceto quatro pais que não permitiram o uso do gravador. Eram, então, transcritas, conservando-se as expressões de linguagem utilizadas pelos entrevistados. Os participantes foram identificados por codinomes iniciados pela letra " $L$ ", mudando-se o gênero: Leopoldina e Leopoldo, Laura e Lauro, Luísa e Luís, Leandra e Leandro e Lúcia e Lúcio. Três mães eram do lar, Laura é comerciante e Luísa estudante de Letras. Leopoldo é torneiro mecânico, Lauro comerciante, Luís açougueiro e Lúcio microempresário. A faixa etária variou de 18 a 33 anos e apenas Laura não era primigesta.

Para análise dos dados, utilizamos a análise temática que significa a descoberta dos núcleos de sentido que compõem uma comunicação, cuja presença ou freqüência signifiquem algo para o objetivo da análise ${ }^{(8)}$. Os núcleos temáticos utilizados para a categorização dos dados obtidos centraram-se em palavras ou sentidos contidos nas falas dos entrevistados.

\section{RESULTADOS E DISCUSSÃO}

A percepção da família acerca dessa vivência no Cuidado Canguru, a partir dos dados obtidos em nosso estudo, foram agrupados em quatro núcleos temáticos: "flexibilizando a permanência materna no Método Canguru", "favorecendo a relação mãe-filho e familiar", "completando o crescimento e o desenvolvimento do prematuro" e "desenvolvendo habilidades para o cuidado do filho".
De modo geral, o relato dos pais acerca de sua experiência no Método Mãe-Canguru foi positivo. A sensibilização e treinamento dos profissionais de saúde nessa metodologia vem sendo ampliada através da organização de eventos técnico-científicos, patrocinados por instituições governamentais e implementados a partir da oficialização normativa do Método Canguru pelo Ministério da Saúde ${ }^{(6)}$. Discutiremos, a seguir, os temas emergidos durante a análise deste estudo.

Flexibilizando a permanência materna no método canguru

O Método Mãe-Canguru foi desenvolvido através de flexibilização no tempo de permanência materno e de negociações entre o enfermeiro e a instituição, tendo sido acordado o horário de início e término, a acomodação e as visitas dos outros familiares ao binômio mãe e filho. Essa organização difere do Método descrito na literatura e implantado em diversos serviços nacionais e em outros países, pois a mãe não permanece internada em tempo integral e nem vai para casa com o bebê em Canguru, como originalmente foi criado em Bogotá( ${ }^{(2)}$. Apesar disso, consideramos que atende à concepção do Ministério da Saúde ${ }^{(6)}$, pois a mãe permanece com o bebê o tempo que for possível e prazeroso, podendo deixar o cuidado de acordo com suas necessidades.

Eu ía e chegava lá às oito horas da manhã e ficava lá até às seis e meia, sete horas da noite. Ficava a tarde inteira (Leandra).

... Aí eu vinha para casa descansar para à noite eu voltar (Lúcia).

A liberdade da mãe em optar pelo momento de retornar ao lar possibilita o desempenho de outras atividades, como é o caso de Leandra, ou simplesmente o descanso em seu domicílio, como verbaliza Lúcia. A flexibilização do horário para a realização do Cuidado Canguru, permitindo que a mãe retorne, à noite, para o domicílio, pode minimizar a ansiedade decorrente do afastamento materno do lar, sentimento esse expresso por algumas mães em estudo realizado em uma instituição que implantou esse Método, de permanência contínua, desde $1994^{(9)}$. A mulher, por desempenhar diversos papéis, simultaneamente, como o de mãe, esposa e dona de casa, dificulta a ausência prolongada do lar e pode conduzir a algumas deficiências no bom encadeamento dos papéis. A flexibilidade do Método desenvolvido possibilita à mãe dividir seu tempo com o filho internado, com os afazeres domésticos, com o parceiro e com os outros filhos, se existirem. 
Mesmo havendo a possibilidade do retorno ao lar, observamos que a ausência materna do domicílio altera a dinâmica familiar, tanto no desempenho de papéis sociais como nas relações afetivas.

É eu não fazia quase nada (em casa) porque eu tinha que ir cedo lá (no Canguru). Só na hora que eu chegasse à noite. Que eu saía de lá às seis e meia, sete horas, né? /.../ (Luísa).

Não era problema ela deixar a casa de lado ... Ela deixou de fazer o serviço de rotina que é cuidar da casa, né?/.../ Para mim não teve danos nenhum /.../ Às vezes até a gente fica um pouquinho largado assim né (Risos). Isso é normal, né? Um esforço pela criança, pelo filho. A gente tem que entender. Sem problemas (Leandro).

Apreendemos que, veladamente, Leandro manifesta certa carência afetiva, apesar de priorizar a recuperação da filha prematura, o que incluía readaptação e esforço coletivo da família, mesmo na ausência de outros filhos, como é a situação desse casal. O filho internado pode gerar desorganização familiar, porque a mãe deixa suas atividades domésticas para permanecer com ele, o que interfere no cuidado dos outros membros familiares. Inicialmente, são manifestados sentimentos de ansiedade, preocupação e dificuldade em conviver com uma criança doente e, mais tarde, a família coloca em segundo plano os objetivos profissionais, principalmente a mulher que, historicamente, é a responsável pelo cuidado da família ${ }^{(10)}$.

As atividades maternas podem ser amenizadas de acordo com a condição socioeconômica familiar. Nas famílias mais favorecidas economicamente, podemos observar que os papéis da mulher são absorvidos por empregados, enquanto ela se dedica mais ao filho. Isso ficou evidenciado com a entrevistada Lúcia que apresenta condição econômica diferenciada em relação às demais famílias participantes desse estudo.

Aqui (em casa) não me atrapalhou em nada a mulher sair (para a realização do Canguru) porque eu tava preparado para isso (Lúcio).

Lúcio é microempresário e, antes da filha nascer, havia planejado, juntamente com a esposa, a redução das atividades dela, que deixara o emprego e trancara a matrícula na faculdade de Letras. As atividades domésticas foram absorvidas por uma empregada e Lúcia, então, se dedicou exclusivamente à filha no Canguru.

Mesmo dispondo de rede de apoio familiar para auxiliar no processo de permanência junto ao filho em Cuidado Canguru, a maneira como foi possível organizálo na instituição também gerou outros rearranjos familiares e certo desgaste materno, conforme mostram as falas.
Eu ficava muito cansada. Muito cansada mesmo. Chegava (referindo-se ao horário) às 3 horas da tarde eu tava muito cansada demais (Lúcia).

Ruim assim era que eu tinha que sair todo dia e ir lá, né. Para mim é um pouco longe, né? /.../ Só a hora que eu chegava (em casa), dormia, descansava e começava tudo de novo /.../ (Leandra).

A família coesa, apóia o casal durante a crise do nascimento prematuro, evitando que as esperanças se reduzam e que as dificuldades aumentem ${ }^{(10)}$. Porém, o fato de ir e vir, diariamente, ao hospital, repercute também no orçamento familiar, pois a dificuldade com o transporte era real em algumas famílias.

O difícil é ir e vir. Dinheiro é difícil. O que facilitou foi o passe até Ribeirão Preto a Sertãozinho (fornecido pelo hospital). Não tinha o passe de Serrana, tinha que pagar (Luís).

Cabe assinalar que Luís estava, recentemente, empregado e o orçamento familiar era muito restrito, ficando mais comprometido com o acréscimo de despesas decorrentes de transporte, apesar de receber da instituição o passe que cobria parte do traslado (Sertãozinho-Ribeirão Preto). Isso também repercutiu na presença paterna, visitando o filho em Cuidado Canguru, o que ocorria a cada 15 dias.

Laura, que não recebia alimentação fornecida pelo hospital e descreve sua rotina.

Eu ia para casa almoçar, voltava para o hospital, depois voltava de novo às 18h30min para o horário da visita. Ainda que para mim não era tão difícil porque eu moro perto (Laura).

Essa entrevistada sinaliza para a necessidade de maior envolvimento das instituições e governos municipais a fim de possibilitar a implantação mais efetiva do Método Mãe-Canguru, e a adequação daqueles já existentes. $\mathrm{Na}$ Portaria do Ministério da Saúde sobre o Método Canguru, é apontada a necessidade de apoio social para as mães que precisam de auxílio para transporte e alimentação. Porém, essa norma não contempla o financiamento dos encargos sociais decorrentes da implantação do Método, como adaptação de leitos hospitalares para a acomodação de mães e familiares, ficando essa responsabilidade para as instituições hospitalares. Nesse sentido, ao envolver custos, as opções ficam cada vez mais restritas e as dificuldades e conflitos acabam ficando sob a responsabilidade do profissional que está na linha de frente e no cotidiano de trabalho junto a essa clientela ${ }^{(6)}$. As dificuldades que vivenciamos, envolvendo negociações com vários setores do hospital, conforme relatamos anteriormente, seriam minimizadas pelo cumprimento da 
normatização proposta para o Método Mãe-Canguru se, na ocasião, integrasse efetivamente a filosofia institucional e houvessem incentivos orçamentários disponibilizados pelo SUS, um efetivo sistema de referência e contrareferência, facilitando o acesso às maternidades localizadas mais próximas do domicílio da clientela. Nesse contexto, outra dificuldade com a manutenção do Cuidado Canguru, tanto na vivência profissional como nas falas de algumas mães, refere-se às acomodações físicas oferecidas pela instituição. Todavia apreendemos nas falas de Leandra e Lúcia.

Recebia muito boa alimentação. Gostei daquele hospital lá. O alimento de lá é muito limpinho. Eles são feitos muito limpinhos. Eu gostava /.../ Tinha cama, ar condicionado, televisão... Era bem confortável... (Leandra).

Acho que devia ter uma cama para a mãe relaxar, umas cadeiras mais confortáveis, poltronas. Sei lá, uma sala mais estruturada para a mãe ficar mesmo. Para a mãe ficar o dia todo e não se cansar tanto. Eu ficava ali (apartamento da Maternidade utilizado para o desenvolvimento do Canguru) o dia inteiro sentada, sentada, sentada (Lúcia).

Existe acentuada diferença socioeconômica entre essas mães. A relação de conforto e repouso para as duas mães é distinta, pois o que uma acredita ser confortável, a outra enxerga como simples demais para oferecer conforto. Cabe lembrar as dificuldades que vivenciávamos pelo fato de não dispormos de área física específica para o Cuidado Canguru, diferenciando as oportunidades oferecidas às mães. Além disso, acreditamos que o Método Canguru deve se constituir em direito e opção da clientela e jamais uma obrigação. A inserção da mãe na assistência ao filho hospitalizado é uma estratégia de aproximação da família, que não deve ser vista como obrigação, trazendo uma concepção de cuidado fragmentado, centrado na tarefa ${ }^{(10)}$.

Se tomarmos como base a estrutura física exigida para a realização do Cuidado Mãe-Canguru pelo Ministério da Saúde ${ }^{(6)}$, veremos que a área hospitalar necessita apenas ampliar o número de camas e berços, de acordo com a demanda e destinar um local específico para esse cuidado. $O$ apartamento que usávamos freqüentemente tinha cama, berço, divã, ar condicionado, TV e banheiro. Por outro lado, a estrutura atende à normatização no que diz respeito à existência de aspirador a vácuo, carrinho de urgência, termômetro, localização próxima do posto de enfermagem e perto da unidade de cuidados especiais. A balança e o material de higiene, citados na normatização, ficam no Berçário onde os bebês recebem, pela manhã, o banho e demais cuidados de higiene. Se oferecermos a essa clientela a oportunidade de atividades lúdicas e pedagógicas direcionadas à orientação materna acerca do cuidado com o filho, associado a um maior conforto, poderíamos amenizar o cansaço materno e otimizar a assistência prestada.

A singularidade do processo vivenciado pelas famílias de bebês de risco, envolvendo os aspectos psicoemocionais já mencionados, com longo período de internação do filho na unidade neonatal, acrescido do fato de que muitas dessas atividades de lazer justificam a implantação de estratégias para atender às suas necessidades. Projeto dessa natureza está sendo desenvolvido desde 1999, no Hospital das Clínicas de Ribeirão Preto em parceria com a Escola de Enfermagem de Ribeirão Preto da Universidade de São Paulo, com o objetivo de experimentar estratégias novas no cuidado de enfermagem através de atividades lúdicas, recreacionais, educativas e dinâmicas de grupo para essa clientela. Os resultados positivos dessa experiência demonstram a satisfação dos pais participantes do projeto, através do alívio de tensões emocionais e da socialização, com troca de experiências, contribuindo com o processo de construção de uma assistência mais integral e humanizada, tendo a família como foco do cuidado neonatal $^{(4,11)}$.

Favorecendo a relação mãe-filho e familiar

A proximidade com o filho prematuro favorece a troca de afetividade e o estabelecimento do vínculo, conforme apontam a literatura $^{(2,12-14)}$ e as falas.

Para mim foi uma experiência maravilhosa de você sentir o calor do seu filho perto de você... (Lúcia).

Eu queria ficar, ter contato, sentir ele juntinho de mim, dentro daquela bolsa (suporte de algodão cru para manter o bebê na posição). Ele era tão pequenininho..., colocou ele naquela bolsa, trocando quentinho dele com quentinho meu, esse carinho foi bom demais (Laura).

Essa troca de calor humano e afetividade entre o prematuro e os membros da família são pontos importantes para o fortalecimento do relacionamento familiar.

Foi bom porque ele (prematuro) teve mais contato um com o outro (referindo-se à mãe). Ficavam quentinho /.../ Eu vendo o contato dos dois. Isso é que é importante /.../ Onde a gente ficava supercontente (Lauro). 
Para a mãe, que vai para casa e chega só, sem seu bebê, existe um sentimento de culpa associado ao fato de não ter conseguido manter a gestação até o final. É uma mãe cujo filho não está presente, não pode ser visitado por todos e cujas condições clínicas não permitem que ela desempenhe os cuidados de maternagem. Pode pensar que os profissionais, que cuidam de seu filho, exercem mais o papel materno do que ela própria. Quando o bebê evolui e permite idealizar, sonhar, ser tocado, aos poucos, ela vai se sentindo segura e incorporando seu papel materno.

Nossa! Foi de muita alegria. Me senti mãe realmente, de verdade... (Leandra).

...Tive mais segurança, me senti como mãe. Quando ele estava na UTI eu não era mãe /.../ Foi muito boa (a sensação de quando o bebê foi colocado pela primeira vez em posição Canguru). A primeira vez que a gente pega se emociona demais, a gente é mãe (Luísa).

À medida que os pais se sentem livres para permanecer o tempo que lhes é possível com o recémnascido assistido em unidades neonatais, eles ficam mais tranqüilos para cuidar, melhorando a qualidade do relacionamento mãe-filho-família ${ }^{(10)}$. Esse relacionamento entre mãe e filho, possibilitado pelo Método Canguru, é também percebido pelas entrevistadas como fator de adaptação recíproca da díade e de preparação para o cuidado domiciliar.

Dela saber me reconhecer, sentir meu cheiro, já se adaptar comigo. Para levar ela pra casa e ela não estranhar /.../ se adaptar à mãe, então eu fazendo o Canguru ela já tava acostumada comigo, eu mais ainda a ela, porque tive mais segurança de trazer ela pra casa (Lúcia).

Tinha mais esperança porque podia pegar no colo, sentir ele. Eu ia levar ele para casa (Luísa).

O momento da alta é temido pelos pais, mesmo que tenham tido a oportunidade de cuidar do filho, existe receio de que algo aconteça no $\operatorname{lar}^{(15)}$. Nessa ocasião, os pais devem ser orientados a não realizar uma superproteção do filho em decorrência de sua necessidade prévia de cuidados intensivos e certos momentos de risco, vivenciados durante a internação ${ }^{(10)}$. Acreditamos que o profissional de saúde deve orientar os pais acerca dos cuidados essenciais e básicos de que cada bebê necessita, mas atentar para atitudes extremas e radicais de modo a desmistificar e esclarecer ao máximo suas dúvidas.
Completando o crescimento e o desenvolvimento do prematuro

O Canguru foi apreendido pelos pais como possibilidade imaginária de retorno do prematuro ao ventre materno, onde o bebê poderia crescer e se desenvolver, completando a gestação interrompida.

Ele se mexia. Arrumava o jeitinho dele. /.../ tinha a posição que mais gostava. Ficava tortinho, encaixava a cabeça, aí a gente ia tentando arrumar, mas ele queria ficar todo torto lá dentro da bolsa, mas era o jeito que ele achava melhor. Parecia que ele tinha voltado para dentro da barriga (Laura).

Como se tivesse dentro da barriga da mãe novamente (Lauro).

/.../ Porque ele (bebê) pensava que tava dentro da barriga e aí ia engordar mais rápido ainda (Leandra).

Em muitas unidades neonatais, o critério ponderal é definitivo para determinar a alta hospitalar. Neste serviço, está estabelecido em $2.000 \mathrm{~g}$ de peso, acrescido da ingesta de toda alimentação láctea por via oral. Isso gera grande expectativa nos pais, pois alguns deles chegavam a controlar rigorosamente cada grama de ganho de peso do filho. Assim, o Cuidado Canguru significou para os pais a possibilidade de favorecer o ganho ponderal mais rápido do filho e, conseqüentemente, alimentava o desejo da alta precoce.

Teve um dia, né amor (dirigindo-se à Leandra), que engordou 80g, dum dia pro outro. Ficava até animado. Se continuasse nesse ritmo aí, rapidinho nós levávamos ela embora /.../ Ganhou, ganhou sim /.../ (Leandro).

Eu achava que ía dar certo e que ajudaria ela a ganhar mais peso. Engordar mais rápido e ficar mais rápido perto de mim / .../ Que ele (Método Canguru) ia ajudar a engordar mais rápido e sair mais rápido do hospital, né? (Leandra).

$\mathrm{O}$ contato mais estreito com o filho, com o acompanhamento de sua evolução clínica e seu crescimento, desencadeiam nos pais sentimento de tranqüilidade.

Nossa, eu nem tava acreditando. Era um presente de Deus. Eu podia ficar com ele. /.../ Fiquei mais contente porque podia ficar com ele o dia inteiro/.../ Fiquei mais tranqüila porque eu tava vendo o que acontecia, eu tava acompanhando o crescimento (Laura).

Ah, eu gostei porque a gente tá perto da pessoa que a gente mais ama que é a nossa filha, né (Leandra).

Desenvolvendo habilidades para o cuidado do filho

O sentimento de medo, verbalizado pelas mães, 
decorre também da execução de cuidados básicos, como pegar o bebê no colo, dar banho e trocar o vestuário, podendo ser atribuído ao tamanho reduzido do prematuro, quando comparado ao de um bebê a termo, cuja fragilidade é apreendida pelas mães sobre a representação social delas acerca do prematuro ${ }^{(9)}$.

Quando eu cheguei em casa eu acho que os ensinamentos delas lá (profissionais do Berçário) foram ótimos pra mim, porque eu aprendi bastante coisa, né. E agora eu tenho facilidade. Graças a Deus e à vocês lá (Leandra).

Não senti dificuldade de cuidar do B. (bebê) porque lá (enfermaria destinada ao Cuidado Canguru) a gente pegava, a gente podia trocar (Laura).

Uma das contribuições do Cuidado Canguru é a de aumentar a confiança dos pais, principalmente das mães, para o cuidado com o bebê, pois se sentem mais tranqüilos, apresentando sentimentos mais positivos relativos ao filho e à preparação para a alta ${ }^{(14)}$. É interessante notar também que alguns pais sentiram diferença no aprendizado das mães relacionado ao cuidado com o bebê, enfatizando as novas habilidades da esposa.

Ela não sabia nada. Não sabia cuidar de nenê. Pegou experiência. Ela aprendeu. Aprendeu muita coisa (Luís).

Ela trouxe o conhecimento de lá (hospital) para cá (domicílio)... muito mais segurança para mexer com a nenê, né? (Lúcio).

O pai, mesmo com todas as transformações por que passa a família, ainda tem demonstrado ter papel subsidiário à mãe no relacionamento e cuidado com o filho ${ }^{(15)}$. Na maternagem, a alimentação constitui prática que gera preocupação e dificuldades, particularmente entre as mães de bebês prematuros. Devido aos riscos, biológico e social, em seu processo de crescimento e desenvolvimento, o aleitamento materno tem sido recomendado e incentivado para os prematuros através de estratégias, dentre as quais a implantação do Método Canguru. A singularidade do processo desenvolvido pela família com o nascimento de um filho prematuro e as limitações anátomo-fisiológicas desses bebês, que dificultam a alimentação, repercutem no aleitamento materno, requerendo da mãe cuidados e empenho para manter a lactação. Etapas desse processo foram verbalizadas pelas mães entrevistadas.

...Eu ficava torcendo para que ele (bebê) sentisse o cheiro do meu leite e pegasse o peito para tirar aquela sonda. Pegou o peito, mamou, mas teve que voltar para sonda (Laura).

Ela (filha prematura) tinha mamado na UTI, mas ela ficou muito cansada, então ela voltou para a sonda (Lúcia).
Nessas situações, a mãe necessita do apoio profissional competente, não só auxiliando com a técnica, para intervir nas intercorrências apresentadas pelo prematuro, mas também mostrando-se sensível às necessidades emocionais maternas nesse processo. Freqüentemente, esses bebês apresentam avanços e retrocessos na alimentação por via oral e, quando em amamentação materna, essas ocorrências podem gerar ansiedade e até o sentimento de culpa nas mães, se não estiverem orientadas e apoiadas pela equipe de saúde. A manutenção da lactação requer empenho da mãe do prematuro, sendo importante inseri-la precocemente no cuidado com a alimentação do filho, mesmo quando administrada por sonda gástrica.

Eu tirava leite todos os horários para dar ao bebê. Eu procurava tirar uma hora antes da mamada para ficar fresquinho (Laura).

Eu tirava o leite e guardava nos copinhos. E passava tudo pela sonda... (Lúcia).

Por outro lado, não podemos negar que esse processo pode ser desgastante para as mães e até gerador de ansiedade, em especial, se a postura dos profissionais que atuam junto a essa clientela for normativa, prescritiva e centrada na criança ${ }^{(9)}$. Para o sucesso na prática do aleitamento materno, nessa clientela, é fundamental também que as intervenções profissionais sejam ampliadas para além do hospital, uma vez que, nele, a mãe sente ser um ambiente controlado, onde qualquer intercorrência com o bebê será prontamente corrigida. No domicílio, a equipe não está presente e a mãe assume total responsabilidade sobre o bebê. Algumas não recebem qualquer apoio familiar e outras contam com a colaboração de uma rede de apoio informal, como parentes, esposo e vizinhos, como cita Leandra.

As meninas (outras mães em Cuidado Mãe-Canguru) me falaram como é que era e me ajudaram muito, mas em casa eu fiquei muito preocupada porque eu não tava perto de vocês (equipe do Berçário), minha mãe perto, minha sogra, o Leandro me ajudavam, falavam que não, que não era assim (Leandra).

O nascimento leva à aproximação das famílias e para a participação de outras pessoas, como os vizinhos, que passam a fazer parte do nascimento. Essa família ampliada é um recurso para a família nuclear com criança pequena, seja em momentos de calma, ou em momentos de perturbação ${ }^{(16)}$. Acreditamos que, se for aberto à mãe um canal para que possa ter uma referência, amenizando suas dúvidas, reduzindo insucessos e as frustrações 
maternas, como, por exemplo, na manutenção do aleitamento materno, poderia haver redução da ansiedade nas primeiras semanas após a alta hospitalar. A normatização descrita pelo Ministério da Saúde preconiza o atendimento ambulatorial da família, terceira etapa do Método Mãe-Canguru, iniciado desde a primeira semana após a alta ou quando a família achar necessário ${ }^{(6)}$. $\mathrm{Na}$ fala que se segue, podemos perceber uma lacuna na continuidade da assistência prestada a esse binômio mãe e filho.

Depois que ela veio para casa não consegui dar mamá nem uma semana direito. Ela chorava muito e não tinha paciência. Meu leite era de gotinha. Eu tentei tirar e dar para ela, saía muito pouco, gota por gota (Leopoldina).

Essa dificuldade quanto à amamentação poderia ter sido minimizada se houvesse uma rede de apoio formal, sistematizada, com seguimento a longo prazo, incluindo consultas médicas e de enfermagem, desde a primeira semana após a alta hospitalar, visitas domiciliares, sempre que necessário, articulação entre as ações interinstitucionais (hospital e rede básica de saúde), serviço de pronto-atendimento clínico em aleitamento materno e atendimento à distância por telefone, para sanar as dúvidas.

Nossa experiência, enquanto enfermeira de UTIN, é a de que os profissionais de saúde sentem-se satisfeitos com o produto final de seu trabalho, ou seja, que o bebê e família sejam capazes de ir para o lar e os pais se responsabilizem pelo filho o mais rápido possível. A integração entre enfermeiras e pais pode minimizar a ausência de uma pessoa de referência para o casal e criar laços de confiança para a cooperação mútua entre as partes e por ocasião da alta hospitalar, prevenir danos à saúde do bebê e possibilitar acompanhamento de seu desenvolvimento e de possíveis seqüelas, gerando tranqüilidade em toda a equipe neonatal ${ }^{(17)}$.

\section{CONSIDERAÇÕES FINAIS}

Nesse estudo relatamos a percepção de um grupo de pais sobre a vivência no Método Mãe-Canguru em hospital filantrópico. A maior dificuldade em manter o Mãe-

\section{REFERÊNCIAS BIBLIOGRÁFICAS}

1. Ludington-Hoe SM, Swinth JY. Development aspects of kangaroo care. Journal of Obstetric, Gynecologic, and Neonatal Nursing 1996; 25(8):691-703.
Canguru refere-se à ausência de uma filosofia institucional dirigida à humanização do cuidado, ao processo de nascimento e ao recém-nascido. Tal fato repercutiu na necessidade de freqüentes negociações entre o enfermeiro, a diretoria e outros setores do hospital, a fim de conseguir área física e alimentação para as mães permanecerem em Cuidado Canguru. Acreditamos que essa problemática será minimizada diante da prioridade atribuída ao Método Canguru nas políticas públicas de perinatal vigentes, na atualidade, tendo sido normatizado pelo Ministério da Saúde, e criado incentivos para sua implantação, treinamentos e sensibilização de gestores de saúde e equipes multiprofissionais atuantes nas unidades neonatais de risco.

Além disso, ressaltamos, ainda, o fato de as instituições de ensino estarem incluindo conteúdos acerca da humanização da atenção perinatal e neonatal e do Cuidado Canguru, na formação dos profissionais de saúde.

A permanência da mãe no Método, na instituição, só foi possível em regime de semi-internação. Estratégia que pode reduzir a ansiedade e os problemas familiares decorrentes da ausência materna no domicílio, mas, por outro lado, repercutiu em mudanças no cotidiano familiar. Para algumas mães de menor poder aquisitivo isso significou certo desgaste físico e emocional e o aumento do gasto com o transporte. Tais dificuldades seriam minimizadas se a instituição oferecesse recursos para o transporte, a alimentação das mães e desenvolvesse trabalho articulado com a rede básica de saúde e outros setores sociais. É fundamental também a participação efetiva da rede de apoio informal junto à clientela, envolvendo amigos, vizinhos, dentre outros.

À luz da Portaria que normatiza a atenção humanizada ao recém-nascido de baixo peso, acreditamos que estamos em fase intermediária do desenvolvimento das duas primeiras etapas previstas. Apesar de não dispormos de área física específica para alojar mãe e filho em posição Canguru e de equipe interdisciplinar completa, consideramos que houve avanços na acolhida da família e aprimoramento técnico e psicoafetivo da assistência, através da prestação de cuidados mais individualizados para o prematuro e sua família, tentando respeitar a singularidade de cada binômio mãe e filho.

2. Charpak N, Calume ZF, Hamel A. O método mãe-cangurupais e familiares dos bebês prematuros podem substituir as incubadoras. Rio de Janeiro (RJ): McGraw Hill; 1999.

3. Ministério da Saúde (BR). Alojamento conjunto[on line] 1982. [2000 julho 10]. Disponível em: www.uniceforg/ brazillavanco.htm. 
4. Scochi CGS. A humanização da assistência hospitalar ao prematuro: bases teóricas para o cuidado de enfermagem. [tese]. Ribeirão Preto (SP): Escola de Enfermagem de Ribeirão Preto/USP; 2000

5. Levin A. Humane neonatal care initiative. Acta Paediatr. 1999; 88:353-5.

6. Portaria $n^{\circ} 693$ de 05 de julho de 2.000. Dispõe sobre a norma para a implantação do método canguru, destinado a promover a atenção humanizada ao recém-nascido de baixo peso. Diário Oficial da União, 5 de julho de 2000.

7. Minayo MCS, Deslandes SF, Cruz Neto O, Gomes R. Pesquisa social: teoria, método e criatividade. $8^{\underline{a}}$ ed. Petrópolis (RJ):Vozes; 1998.

8. Minayo MCS. O desafio do conhecimento: pesquisa qualitativa em saúde. 3a ed. São Paulo (SP): Hucitec- Abrasco; 1994.

9. Javorski M. Os significados do aleitamento materno para as mães de prematuros em cuidado canguru. [dissertação]. Ribeirão Preto (SP): Escola de Enfermagem de Ribeirão Preto/ USP; 1997.

10. Gomes MMF. As repercussões familiares da hospitalização do recém-nascido na Unidade de Terapia Intensiva Neonatal: construindo possibilidade de cuidado. [tese]. São Paulo (SP): Escola Paulista de Medicina/ UNIFESP; 1999.

11. Scochi CGS, Costa IAR, Yamanaka NM. Evolução histórica da assistência ao recém-nascido: um panorama geral. Acta Paul Enfermagem 1996; 9(número especial): 96-101.

12. Montagu A. Tocar: a dimensão humana da pele. São Paulo (SP): Summus; 1988.

13. Valdés V, Sánchez AP, Labhok M. Manejo clínico da lactação: assistência à nutriz e ao lactente. Buenos Aires (AR): Revinter; 1996.

14. Bergman NJ, Judgo LA. The "kangaroo-method" for treating low birth weight babies in a developing country. Tropical Doctor April 1994; 24:57-60.

15. Gaíva MAM. Cotidiano de escolares nascidos prematuros: percepção de crianças e familiares. [dissertação]. Ribeirão Preto (SP): Escola de Enfermagem de Ribeirão Preto/USP; 1997.

16. Monticelli M. O nascimento como um rito de passagem: uma abordagem cultural para o cuidado de enfermagem às mulheres e recém-nascidos. [dissertação]. Florianópolis (SC): Universidade Federal de Santa Catarina; 1994.

17. Barbosa VL. Conhecimentos e opiniões de enfermeiras sobre a participação da mãe na assistência ao recémnascido prematuro. [dissertação]. São Paulo (SP): Escola Paulista de Medicina/UNIFESP; 1990. 